\title{
A FiguRA DA ILUSÃO NA LITERATURA PSICANALÍTICA DA RELIGIÃO ${ }^{1}$
}

\author{
Mario Aletti ${ }^{2}$ \\ Università Cattolica di Milano
}

Este trabalho acompanha a história e evolução do modelo da ilusão aplicado à vivência religiosa, a partir das concepções de Freud, Pfister, teóricos das relações objetais, Winnicott, Vergote e Rizzuto, delineando as perspectivas abertas por essas contribuições teóricas, bem como seus limites.

Descritores: Psicanálise. Religião. Psicanálise e religião.

Na realidade, a psicanálise constitui um método de pesquisa, um instrumento imparcial (...) Se a aplicação do método psicanalítico torna possível encontrar um novo argumento contra as verdades da religião, tant pis para a religião, mas os defensores desta, como o mesmo direito, poderão fazer uso da psicanálise para dar valor integral à significação emocional das doutrinas religiosas. (Freud, 1927/1987, p. 45)

1 Conferência proferida no Instituto de Psicologia da Universidade de São Paulo e no Programa de Pós-Graduação em Psicologia Clínica, da Pontifícia Universidade Católica de São Paulo, nos dias 10 e 12/09/2002, no quadro do $4^{\circ}$ Seminário Psicologia e Senso Religioso, "Processos psicológicos na representação religiosa", com o auxílio da FAPESP. Tradução de Geraldo José de Paiva.

2 Membro da Società Italiana di Psicologia della Religione. Endereço eletrônico: Mario.aletti@iol.it. 
$\mathrm{O}$ título de minha contribuição se vincula e se põe em continuidade crítica com uma categoria interpretativa freqüentemente utilizada na literatura psicanalítica da religião, especialmente na célebre obra de Freud, de 1927, O futuro de uma ilusão, e em seu contraponto polêmico, o ensaio $A$ ilusão de um futuro, de Oskar Pfister, publicado no ano seguinte, por vontade do próprio Freud, em Imago.

A figura hermenêutica da ilusão, como a da projeção, acompanha desde sempre a reflexão do homem acerca da religião. A antiga ironia de Xenófanes sobre a figuração antropomórfica dos deuses ("Se os cavalos tivessem mãos, pintariam imagens dos deuses semelhantes a cavalos") ecoa com tonalidades diversas e com resultados vários, também no rico e fecundo filão da pesquisa psicanalítica das vivências religiosas. A função iconoclasta da psicanálise oscila, aqui, periodicamente, entre uma polaridade reducionista e niilista e uma outra purificadora e, em alguns casos, também apologética (Aletti, 1998, 2000b).

\section{A partir do início: Freud, Pfister, Salomé}

No que respeita a Freud, a tese principal, a que permanecerá sempre fiel até os três ensaios sobre Moisés e o monoteísmo (Freud, 1934-38/1975), já se expressa na carta a W. Fliess, de 12/12/1897, no qual define os conteúdos da religião como "mitos endopsíquicos" e explica: "A imortalidade, a recompensa depois da morte, o além no seu conjunto: são todas representações de nosso interior psíquico. Idéias loucas? Psicomitologia?" (Freud, 1887-1904/1986). 
Certamente, não se trata, para Freud ${ }^{3}$, de delírio, nem necessariamente de erro. Mas seguramente de uma construção projetiva, como irá precisar em Psicopatologia da vida cotidiana: "Creio, com efeito, que grande parte da concepção mitológica do mundo, que se estende difundindo-se até às religiões mais modernas, não seja outra coisa que psicologia projetada no mundo externo" (1901/1976).

Tarefa da psicanálise é a de retransformar tal "construção de uma realidade suprassensível" em uma "psicologia do inconsciente". Empresa grandiosa, que abre novos horizontes para a relação entre psicologia e teologia: "Poderíamos nos aventurar a resolver desse modo os mitos do paraíso e do pecado original, de Deus, do bem e do mal, da imortalidade, e semelhantes, traduzindo a metafísica em metapsicologia" (1901/1976). Completar-seá, assim, o percurso que visa a mostrar que "o homem criou Deus segundo a própria imagem". Isso será, depois, precisado no conhecido e muito citado passagem de Leonardo da Vinci e uma lembrança de sua infância (1910/1969): "A psicanálise nos ensinou a reconhecer a interconexão existente entre complexo paterno e fé em Deus, indicournos que o Deus pessoal outra coisa não é, psicologicamente, que um pai mais poderoso". Projeção de experiências infantis de proteção e de cuidado ${ }^{4}$, Deus é o precipitado da nostalgia do pai, que todo homem leva consigo na vida adulta, procurando perpetuar uma visão da vida como se fosse um "jardim da infância".

Na obra mais tardia, explicitamente dedicada a essa argumentação, $O$ futuro de uma ilusão, Freud define a ilusão como crença fundada no desejo: "Dizemos portanto que uma crença é ilusão quando em sua motivação prevalece a satisfação do desejo e prescindimos, por isso, de sua relação com a realidade, exatamente como a própria ilusão renuncia à sua convalidação"

3 Illusion não é delusion, segundo a eficaz tradução da passagem de Die Zukunft einer Illusion proposta pela Standard Edition, que brinca seja com a assonância seja com a etimologia latina.

4 E, portanto, de uma relação simbólica, não de uma figura real e histórica. O falso entendimento, operado por certos seguidores apressados, denuncia a dificuldade de um uso do "pensamento psicanalítico" fora do seu contexto de conteúdo e de finalidade. 
(Freud, 1927/1987). Se é impossível pronunciar-se quanto a seu valor de realidade, as ilusões são irrefutáveis, não menos que indemonstráveis, em termos racionais e, daí, não são filosoficamente falsas. Ao fim, porém, na convicção de Freud, não existe outro futuro para a ilusão religiosa que o de desaparecer progressivamente do patrimônio cultural da humanidade, stcumbindo ao progresso científico que avança com a necessidade fatal dos processos de crescimento.

Na realidade, e para além das expressões verbais, a ilusão (e não só a religiosa) é vista por Freud como procedimento de engano, um auto-engano da psique que se recusa a medir-se com a realidade, qual se apresenta ao intelecto do homem. Por isso, embora admita que "assim como ninguém pode ser obrigado a crer, ninguém pode ser obrigado a não crer", condena como culpa contra o "reto pensar" a ligeireza com que alguém esteja disposto a crer em afirmações não demonstradas racionalmente: "A ignorância é ignorância; dela não deriva nenhum direito de crer em coisa alguma". Com isso, confirma uma visão unilateral e redutora das modalidades do conhecer e do saber.

Bem o havia percebido o pastor Pfister que, no ensaio de 1928, evidenciando a natureza teórico-filosófica, e não psicanalítica, da posição de Freud, lhe opõe, como fideísta, A ilusão de um futuro de uma ciência que tenha como referente apenas a si mesma (cientismo), sem se fundar em alguma visão do mundo e sem reconhecer a "dimensão desejante" do pensamento humano.

Uma das maiores heranças que Pfister deixa para a teorização psicanalítica - herança sem beneficiários diretos ou, ao menos, sem reconhecimento, até hoje - deve ser procurada, exatamente, nessa solicitação de uma hermenêutica dos afetos, que um certo racionalismo de Freud tendia, talvez, a subvalorizar.

E é nessa revalorização do mundo dos afetos e dos desejos, enraizamento comum das mais profundas experiências humanas, que se dá valor à convicção de Pfister relativa à função iconoclasta e purificadora da psicanálise, expressa na carta a Freud de 9/2/1929: “A incredulidade é simplesmen- 
te uma fé negativa. Não creio que a psicanálise exclua a arte, a religião, a filosofia, mas que contribua, ao contrário, para purificá-las" (Freud, 190939). Essa passagem, lida em sua inteireza e relacionada com o complexo da teorização de Pfister, não se reduz a um testemunho ingenuamente entusiasta e desajeitadamente apologético, mas eleva-se à dignidade epistemológica e indicação heurística: fé e incredulidade se enraízam, ambas, no mundo dos afetos e do pensamento desejante, de onde retiram sua verdade (psicológica).

Infelizmente, como acenava, para a teorização de Pfister deve-se falar de riqueza sem herdeiros, visto o esquecimento que na literatura e na história do movimento psicanalítico ainda envolve sua figura e sua imensa produção. Destino análogo ao que tocou a Lou Andreas Salomé, ainda mais atenta a dar ênfase à sua própria experiência de vida e a revalorizar, na reflexão teórica, as circunstâncias afetivas e os co-envolvimentos relacionais do conhecimento 5 .

É exatamente a partir de Salomé, que confessava a Freud sentir-se um pouco "herética", que tem início um repensar profundo da figura da ilusão, que se revelará de grande utilidade para compreender algumas experiências fundamentais do homem - em particular, a experiência estética, a erótica e, precisamente, a religiosa -, que atingem, todas, o que de outra forma é inefável, libertando as potencialidades da fantasia e da criatividade.

Salomé reivindica a originalidade e a irredutibilidade das ilusões às explicações fornecidas pelo discurso lógico racional. E, exatamente, com referência à religião, escreve numa passagem de Mein Dank an Freud (Carta Aberta a Freud): "jamais seria possível reduzir o alcance dessa experiência por meio das luzes da razão, reduzir o 'delírio' por meio da 'verdade' no sentido intelectual" (Salomé, 1931.).

5 Pfister e Salomé são duas figuras de grande relevo, que merecem ser estudadas por suas contribuições teóricas e não podem ser escotomizadas como personagens estranhos e um pouco incômodos. Creio que a história do movimento psicanalítico não pode ser feita sem ser confrontada - enquanto história e enquanto psicanalítica - com o que Michel Foucault chamava de "arqueologia do silêncio". 
A afirmação é aplicável ao homem de fé, ao enamorado, ao artista (e por que não, acrescento eu, ao psicanalista?) que experimentam que a via dos afetos e da "ilusão" não é um modo derivado, ou desviado e autoenganador de conhecimento da realidade, mas um outro modo, original e diverso do racional, modo da certeza ìmediata, mas não mais fraco nem menos confiável, nem menos rico de possibilidades de comunicação e de transformação do real ${ }^{6}$.

Para Salomé, o processo da fé confina com o da criação atística e ambos brotam de um estado de narcisismo arcaico originário, que funda aquela experiência de bem-estar que o amor, a religião, a arte procuram, de certa maneira, reconstituir, numa experiência vivida na qual a realidade interna e a realidade externa não são percebidas como separadas. Por exemplo:

A toda obra de arte atribuímos impressões que não podemos receber de nenhuma realidade externa e que todavia nos comunicam algo que não é apenas fruto da subjetividade, mas parece fundado objetivamente. É exatamente isso que, nos sistemas filosóficos, faz elevar a "estética" até às esferas da metafísica.

A arte não necessita de satisfação na realidade: ao contrário, ela retira exatamente da frustração do desejo a tensão para alcançar as culminâncias do percurso criativo. Num processo análogo, a fé se subtrai às figurações de Deus por ela mesma criadas. Porque o verdadeiro crente, não o "sedentário" que se acomoda numa religião recebida passivamente, mas aquele que na elaboração religiosa pessoal "se faz criador de seu Criador", sabe que está sempre arriscando a idolatria das imagens. Pelo que, "essa fé [madura], a única que não é objeto de abuso e que é absolutamente completa, convém apenas ao homem da dúvida", aquele que, no próprio pronunciamento de fé, é acompanhado da "suspeita de ter trocado de Deus, de tê-lo ofendido abandonando-o, como presa, à terrenidade", na consciência de que a figuração de Deus já é "um nome para um vazio".

6 Vem aqui à mente, Vicente van Gogh, que escrevia ao irmão Théo: "Meu grande desejo é aprender a refazer a realidade. Quisera que minhas telas fossem inexatas e irregulares, que se tornassem mentiras, mas mentiras mais verdadeiras do que a verdade literal". 
Ocorre compreender que o culto de Deus é um nome para um vazio, para uma lacuna da devoção, onde já estão presentes a perda e a renúncia, uma necessidade de Deus porque não se possui a ele, enquanto em última instância Deus não poderia existir como tal senão lá onde não há "necessidade" dele. Quem quiser servir-se dele, não mais terá a "Deus", mas alguma coisa que se aponta com o dedo, para forçá-lo a assumir de um modo ou de outro uma forma visível, terrena, intercambiável.

Para Salomé, a fé, quando experiência autêntica, é projeção de um desejo inconsciente; ao mesmo tempo, evocação nostálgica da plenitude originária e percurso criativo e assintótico em direção a uma meta inalcançável.

\section{Ilusão, self e religião na perspectiva relacional}

Se o pastor Pfister e Salomé reivindicam para a ilusão uma função positiva, baseando-se em argumentações "externas" à psicanálise (epistemológicas, antropológicas e também éticas), que a subtraem ao reducionismo cientificista de Freud, é com Donald W. Winnicott que a figura da ilusão se torna categoria central da teorização do funcionamento psíquico, lugar de construção da realidade, e não apenas porta de acesso ao mundo psíquico (muito menos, obstáculo na soleira).

A contribuição de conhecimentos, métodos e modelos oferecidos por Winnicott para a elaboração psicanalítica está estreitamente ligada à introdução de novos paradigmas epistemológicos que, partindo de uma visão estrutural ("o centro de gravidade do ser não tem início no indivíduo, mas numa organização total") e relacional da criança observada na prática pediátrica e clínica ("nunca vi uma coisa chamada criança": a criança é sempre uma criança-com, uma figura de cuidado), chegam a formalizar um modelo geral das relações de objeto.

Nesse contexto de complexidade estrutural e relacional, a figura da ilusão indica a tensão do sujeito para um objeto que se lhe põe diante e, exatamente nesse dar-se para ser possuído, confirma e reforça a tensão relacional. ("A criança cria o objeto, mas o objeto estava lá, à espera de ser criado e de tornar-se um objeto investido de carga", 1975). Para Winnicott, nossas 
ilusões são nossas iluminações. A ilusão não é um erro, tampouco uma verdade; mas o lugar de surgimento do verdadeiro, porta aberta para um percurso.

Nesse sentido, o self surge de uma matriz relacional ilusória, ao longo de uma linha processual, que vai da onipotência alucinatória (sustentada pela cumplicidade da mãe que satisfaz as necessidades da criança, tão logo se manifestem) à percepção mais realística, na qual a criança, atravessando o drama da frustração dos desejos, aprende a reconhecer e aceitar os limites do self e a existência autônoma do diferente de si. A gradual diminuição da adaptação materna é essencial para o desenvolvimento da separação, da diferenciação e da autonomia.

Etapa fundamental nesse processo de crescimento é a experiência transicional. O termo se refere a uma "área intermediária de experiência" e ao uso que a criança faz de objetos que não são parte de seu corpo, mas que ainda não são plenamente reconhecidos como pertencentes à realidade externa (1975).

Objetos especiais, intensamente investidos de desejo, os objetos transicionais (ursinho de pelúcia, boneca, cobertor; mas também uma simples mecha de lã, ou uma palavra, uma tonalidade, um ritual) dão início na criança a uma relação entre o self e o mundo externo. O objeto transicional, de fato, agiliza o desenvolvimento do self mediante a percepção da própria separação e, ao mesmo tempo, da própria ligação com o objeto externo ("É meu!'). Nesse contexto, realidade e ilusão não são vistas como contraditórias; inversamente, a ilusão se apresenta como âmbito germinativo, momento basilar do processo de constituição da realidade interna e externa.

Mas a experiência transicional não é característica exclusiva dos estádios iniciais do desenvolvimento da criança, e a ilusão se reencontra no adulto como refúgio na vagabundagem dos pensamentos, lugar de suspensão da lógica racional, capacidade de brincar com as próprias fantasias e, também, com as realidades da vida circunstantes (pessoas, coisas, afetos e pensamentos...) de maneira criativa: não só refúgio nostálgico e regressivo, mas lugar originário da experiência pessoal mais profunda; da experiência erótica, da intuição estética, da fé religiosa. 
Uma das funções fundamentais dos objetos transicionais, a de favorecer "a tarefa de aceitação do real", fazendo a ponte entre o mundo subjetivo e a realidade objetiva, acompanha a vida toda do homem:

Tem-se aqui, como suposto, que a tarefa de aceitação-da-realidade nunca está completa, que nenhum ser humano está livre da tensão de pôr em relação a realidade interna com a realidade externa, e que o alívio dessa tensão é providenciado por uma área intermediária de experiência que nunca é posta em dúvida (arte, religião, etc.). Essa área intermediária está em continuidade direta com a área da brincadeira da criança pequena, que fica "perdida" na brincadeira (1975).

Winnicott, depois de ter insistido em que "os objetos transicionais e os fenômenos transicionais pertencem ao reino da ilusão, que está na base do início da experiência", amplia o elenco exe mplificativo dos fenômenos culturais: "essa área intermediária de experiência [...] por toda a vida é mantida na intensa experiência que pertence às artes, à religião, ao viver imaginativo e ao trabalho científico criador".

Deve-se destacar, no entanto, que Winnicott não diz, propriamente, que as experiências transicionais na criança pré-verbal sejam a mesma coisa que as do adulto. Ele parece falar de uma continuidade funcional da "área intermediária", embora se refira à evolução das manifestações: "existe uma linha direta de desenvolvimento a partir dos fenômenos transicionais à brincadeira, da brincadeira ao jogo compartilhado, e desse às experiências culturais" (1975).

Winnicott nunca se interessou pela religião como tema e os poucos acenos que ele faz à religião visam apenas a colocá-la entre os múltiplos fenômenos transicionais do mundo do adulto.

Também o surgimento da religiosidade individual é visto em função de (e em continuidade com) as características gerais do desenvolvimento do self. Basta recordar que, em 1967, chamado a proferir uma conferência sobre a evangelização na família, surpreendeu o auditório falando quase exclus ivamente dos cuidados pré-verbais, a partir da importância decisiva da maneira como a criança é segurada nos braços. Só um "ambiente facilitador', que se pode resumir na expressão "mãe suficientemente boa", e daí confiá- 
vel, permite aqueles processos de amadurecimento e de crescimento na confiança (Winnicott, 1982), que estão na base da possibilidade de "crer em" e, ao mesmo tempo, da "capacidade de ficar sozinho". E é só em continuidade com a experiência pré-verbal da "confiabilidade humana", colhida no sentirse abraçado, que a criança estará em condição de aproximar-se do conceito de "braços eternos" de Deus (Winnicott,1989).

\section{Com Winnicott, além de Winnicott}

Entre os autores que receberam a lição de Winnicott sobre a ilusão como porta de acesso à experiência religiosa não faltam os que procuram um caminho de reconciliação e diálogo entre psicanálise e teologia, às vezes, com algum deslize epistemológico ditado pela urgência apologética. Basta, aqui, acenar às obras de dois dentre os primeiros teóricos das relações objetais que se interessaram pela religião, Ronald Fairbairn (1955) e Harry Guntrip (1956, 1969). Partindo da asserção da comum matriz relacional que se pode encontrar tanto na religião como na psique, eles chegam a considerar religião e psicoterapia como equivalentes, ou mesmo como capazes de transformar-se uma na outra. Guntrip, que, na psicanálise, procurava também maneiras para desenvolver melhor sua missão de pastor, chegava a considerar a religião a forma mais alta possível de relação psíquica, termo de confronto e medida de qualquer outra relação humana. Hoje, ao menos para os especialistas, não se mostram mais passíveis de proposição tais apresentações confusas da relação entre psicologia e religião, mas em ambientes eclesiásticos, especialmente de diversas denominações protestantes americanas, elas são encontradas com freqüência, tanto na praxe pastoral como nas reflexões teóricas que fazem parte da "Pastoral Psychology" ou da "Pastoral Care".

Nos últimos decênios, o progressivo deslocamento, na clínica e na teorização psicanalítica, da perspectiva pulsional para a perspectiva relacional tem oferecido novos paradigmas e pontos de vista também para a leitura do posicionamento do indivíduo frente à religião. 
O foco da observação da religião veio-se deslocando do conteúdo de verdade (como se se pudesse verificá-lo ou refutá-lo mediante a análise) para a modalidade relacional que a religião espelha e/ou instaura. Abriu-se, assim, o caminho para considerar a religião como um sistema de objetos internos, que desenvolvem uma função de "continentes" dos sentimentos, pensamentos e fantasmas elaborados pelo indivíduo. Como objetos internos, eles interpelariam a psicanálise não no plano de seus referentes externos e reais, mas por sua função heurística e de adaptação ao mundo humano (Black, 1993). Por discutível que seja o uso extrapolativo do conceito de objeto interno, a esse e outros autores deve-se o mérito de haverem proposto a relevância de um estudo da religião do indivíduo, de terem, em outras palavras, reconduzido o vivido religioso à área de matéria digna e própria da psicanálise. (Operação não garantida, nem banal, se se pensa na praxe clínica corrente e na posição contrária expressa por alguns grandes mestres, de que temos escutado ecos recentes, na Itália. Argentieri, 2000).

Para restituir à psicanálise o vivido religioso, dela indevidamente subtraído com motivações diversas por portadores de diferentes ideologias ("religiosas" ou "psicanalíticas"), tem contribuído inicialmente a atenção suscitada pelas obras de Vergote: Psychologie religieuse (1966) e Dette et Désir (1978; trad. inglesa, 1988) e de Leavy, In the image of God (1988), amplamente apresentadas em órgãos oficiais da instituição psicanalítica internacional (Wallace, 1991). Decisivo foi, a seguir, o amplo debate aberto, sobretudo a partir das obras de Rizzuto (1979, 1996, 1998a, 1998b), na literatura anglo-saxã (Beit-Hallahmi, 1995, 1996; Finn \& Gartner, 1992; Jacobs \& Capps, 1997). A questão está proposta, novamente, de maneira articulada e aprofundada no recentíssimo volume Does God help?, organizado por Akhtar e Parens (2001), com contribuições de numerosos psicanalistas americanos, que dá conta de um debate extremamente rigoroso e franco sobre a religião no curso do tratamento psicanalítico.

Entre os primeiros a colher a fecundidade e as promessas implícitas no modelo winnicottiano para o estudo do vivido religioso, destaca-se a figura de Paul W. Pruyser, americano de origem holandesa, presidente, por diversos anos, da prestigiosa Society for the Scientific Study of Religion 
(Pruyser, 1968, 1974, 1983 e a ótima seleção de artigos republicados por Malony e Spilka, 1991). Enfatizando a derivação etimológica de "ilusão", de in-ludere, onde o "brincar" é reforçado pelo prefixo intensivo "in", ele qualifica a ilusão como "brincadeira empenhada e séria" (Pruyser, 1983, p. 68), como o é, de fato, a brincadeira da criança, que transforma um objeto inanimado em um trenzinho, ou o empenho dos atores que representam um papel na cena do teatro.

No adulto, a ilusão aparece como um expressão específica da brincadeira "produzida pelo homem civilizado enquanto ente dotado de imaginação" (p. 69). Nesse quadro, arte, religião e também as construções científicas são ilusões, funcionalmente equivalentes, na economia psíquica do indivíduo inserido em um contexto cultural, aos fenômenos transicionais da criança.

O mundo da ilusão (illusionistic world), que se coloca como intermediário entre o mundo da realidade percebida pelos sentidos (realistic world) e o mundo dos objetos internos, idiossincráticos (autistic world), do ponto de vista dos processos psíquicos em jogo, é "o mundo da brincadeira e da imaginação criadora, onde o sentir não está em contraposição com o pensar" (Pruyser, 1976, p. 334) e é o mundo dos objetos "transcendentes", prefigurados pelo objeto transicional da criança (que, não por acaso, lhe dedica uma atenção quase religiosa). Aqui, Pruyser fala de objetos transcendentes com referência a todo o vasto campo da cultura humana (1983, p. 67), quer dizer, àquele conjunto de significados que os homens produzem a partir da imaginação e da brincadeira, que pode ser socialmente compartilhado e criativamente inovado pelo indivíduo, embora no interior de uma "tradição", que é dada. No âmbito religioso, isso significa um posicionamento de busca jamais terminada num universo atravessado pelo Mistério e com significados elaborados pelo homem, e não a aceitação aquiescente de um "dado" revelado de uma vez por todas e sancionado pelo dogma.

A resolução do transcendente no transicional e um ou outro esquematismo, especialmente na elaboração das categorias dos três "mundos", assinala no autor o privilégio concedido às urgências práticas e operativas em comparação com a finura da reelaboração teórica e das delimitações episte- 
mológicas. Análoga preocupação, principalmente, pragmática, parece animar, também, a denúncia dos possíveis resultados patológicos das vicissit udes dos objetos transicionais religiosos, com as eventuais distorções autísticas e realísticas dos processos da ilusão que, no conjunto, acabam constituindo uma espécie de psicopatologia da religião, a que Pruyser oferece uma resposta mediante o entrelaçamento (mas diria, também, a confusão!) da cura pastoral e da psicoterapia.

Não isenta de concordismos epistemologicamente discutíveis e, no fundo, direcionada por uma cripto-apologética é, certamente, a obra do jesuíta, psicanalista e teólogo William W. Meissner (1984, 1987, 2001), empenhado na reflexão teórica sobre "a interação e a integração das perspectivas psicanalíticas com as formas religiosas do pensamento e com os sistemas de crença" das igrejas institucionais (Meissner, 2001).

Partindo da convicção de que "a psicanálise conseguiu sustentar uma visão da ilusão como depositária da criatividade humana e como realidade, na qual a potencialidade do homem encontra sua expressão mais alta" (Meissner, 1984, p. 183), ele pretende mostrar como a religião em seu conjunto se coloca na área transicional, à qual se acede mediante a experiência ilusória. Analisa, para isso, a dimensão transicional de alguns elementos fundamentais da experiência religiosa: a atitude de fé, a representação individual de Deus, o simbolismo e a oração, mostrando seus resultados maduros e delineando com eficácia suas possíveis perversões. Mais frágil se mostra o ambicioso projeto de Meissner de propôr um esquema evolutivo psicanalítico da experiência de fé, determinando suas fases, dimensões de desenvolvimento, tipologias. A leitura proposta resulta eclética e concordista, ao integrar diversas teorias psicológicas, não isenta de desvios epistemológicos, quando propõe uma "Psicologia da Graça" e, carência importante numa obra de "psicologia psicanalítica", distante da prática clínica. 
Entre os autores que têm aplicado o modelo da ilusão e, mais em geral, a teoria das relações objetais à religião, destaca-se a figura de Ana-María Rizzuto, cuja obra se impôs à atenção internacional desde 1979, com a publicação de The birth of the living God. Solidamente ancorada na prática clínica e bem distante da tentação de discursos exaustivos sobre a religião (e menos ainda, sobre Deus), ela limita o próprio aprofundamento à formação, evolução, transformação e uso da representação psíquica de Deus, ao longo do ciclo de vida, reconduzindo tal representação de Deus à dialética entre as representações do self e as representações objetais primárias.

Remetendo a outras contribuições para uma apresentação mais artic ulada de seu pensamento (Aletti, 2000a, 2000c, 2001), limito-me, aqui, a sublinhar alguns elementos particularmente caracterizadores e fecundos de sua teorização. Rizzuto considera a representação de Deus como um objeto transicional ilusório (em termos winnicottianos), mostra sua origem e sua função psíquica ao longo de todo o ciclo de vida, afirma sua universalidade, ao menos de fato, em nosso contexto cultural, e sublinha sua incidência na formação de um posicionamento frente a Deus e à religião.

Para Rizzuto, iludir-se significa "brincar" com a realidade, assim como esta se apresenta ao sujeito através do filtro de sua capacidade imaginativa; o objeto religioso ilusório necessariamente remete a uma representação. "A projeção e a ilusão são componentes essenciais de qualquer objeto religioso. E no entanto não são suficientes. A projeção é um mecanismo psíquico e pode projetar somente as representações que encontra. Levanta-se, então, a pergunta de como se formaram a representação projetada ou o objeto trans icional ou a ilusão" (Rizzuto, 1992).

O trabalho de Rizzuto encontra, por isso, uma prioridade lógica e metodológica na revisitação do conceito de representação na literatura psicanalítica. Ela sublinha com força que representações objetais e representação do self são processos de memória compostos, prevalentemente inconscientes e pré-conscientes, que se desenvolvem e interagem entre si, e que se originam 
da adaptação do organismo biopsíquico ao ambiente. A representação evoca, deixando ao ego a tarefa de organizá-las, memórias de todo nível do organismo psicofísico: a partir de memórias viscerais, as sensório-motoras, proprioceptivas, eidéticas, icônicas e, mais tarde, também conceituais. E mesmo se as memórias "primitivas" dificilmente podem ser evocadas sob forma de uma lembrança consciente, elas persistem, quem sabe numa posição do corpo, uma postura, um hábito comportamental, que inconscientemente perpetuam as experiências com aquele objeto.

No processo de análise, a representação de Deus pode, às vezes, revelar-se de maneira inteiramente privilegiada e podem evidenciar-se os processos dinâmicos primários que contribuíram para a formação da representação atual do paciente. Também pode ser possível seguir as transformações de tal representação. A própria Rizzuto, nos numerosos casos clínicos que muito oportunamente sustentam suas formulações teóricas, mostra como mudam, no curso do tratamento, as relações e as representações religiosas, conforme as modificações das relações objetais e as vicissitudes da transferência (Rizzuto, 1979, 2001). Porque, recorda Rizzuto, "o analista, como objeto transferencial e real, ocupa o locus parentis, posição que favorece no paciente o despertar daquelas emoções fortes que estão vinculadas a sua representação de Deus" (2001).

Uma área temática particularmente estimulante na obra de Rizzuto é a da distinção e da relação entre a representação de Deus, de natureza emine ntemente inconsciente ou pré-consciente, enraizada nas dimensões do processo primário, e a figuração de Deus e/ou o conceito de Deus, elaborados no nível do processo secundário. Questão que se torna mais relevante sob o perfil pragmático, mas também mais intrigante sob o perfil teórico, quando se declina como tema das relações entre representação de Deus e adesão pessoal de fé ou ateísmo. Rizzuto concorda com Freud que a fé se estrutura num processo consciente, mesmo que se enraíze em representações do self e dos objetos de natureza pré-consciente ou inconsciente. Certamente, ela está bem avisada de que a formação psíquica de representações de Deus não determina, enquanto tal, a fé em Deus. Pelo contrário, "crença e descrença são sempre o resultado de processos dinâmicos em que o senso do self e a 
representação prevalente de Deus estão ligados numa dialética de compatibilidade ou incompatiblidade na satisfação das necessidades relacionais" $(2001)^{7}$.

Mas, e aqui o pensamento de Rizzuto diverge do de Freud, a representação objetal de Deus, que se forma na infância, conhece também, a seguir, uma história e uma transformação dinâmica. A isso alude o título do volume O nascimento do Deus vivo: "Durante o desenvolvimento, todo indivíduo produz uma representação de Deus idiossincrática e altamente personalizada, que tem origem nas relações objetais, nas representações do self em desenvolvimento e no sistema de convicções de seu ambiente" (Rizzuto, 1979). Portanto, numa semelhante perspectiva epigenética, "a representação de Deus é mais que os fundamentos sobre os quais foi construída" (1979). Ela retoma em si as funções da imago parental de consolação e ajuda, e também de controle e guia, mas não se esgota nelas. A representação de Deus é na realidade composta e sobredeterminada: concorrem para ela, numa interação dinâmica, as relações com os objetos primários, o conflito edipiano (e o gênero sexual a partir do qual se vive esse conflito), as características pessoais dos genitores e as modalidades da interação real entre eles e a criança, a experiência dos irmãos, o ambiente sócio-cultural e, também, circunstâncias específicas e individuais que podem acompanhar o momento em que se forma a representação.

Considerando bem, na inteira obra de Rizzuto, a atenção clínica e a acentuação da idiossincrasia e da dinâmica da representação de Deus e de seu flutuar entre processo primário e processo secundário sugerem que, na realidade, $O$ nascimento do Deus vivo delineia o âmbito e propõe os percursos possíveis do "nascimento do homem que crê", (Aletti \& Ciotti, 2001).

7 Destaco, ainda uma vez, que o mesmo vale para o ateu. Também o não-crente tem uma representação própria de Deus, com a qual tem de se haver de algum modo. $\mathrm{O}$ processo, segundo o qual Deus é "um pai mais poderoso", vale também para quem não crê na existência de um Deus, mas de quem tem, de algum modo, uma figuração. 


\section{Perspectivas e limites.}

Uma visão de conjunto dos escritos dos autores que aplicaram o modelo da ilusão às vivências religiosas permite identificar, embora dentro das diferenças, algumas aquisições comuns, tanto de conteúdo quanto de método.

Antes de tudo, o enraizamento do posicionamento frente à religião (fé ou não crença) nas experiências parentais precoces; enraizamento desligado de valorações preconceituosas negativas (imaturidade, neurose, primitivismo), embora não se apresente isento de ambigüidades (como, de resto, acontece com toda outra experiência humana que tenha a ver com as vicissitudes do Édipo e/ou com o "romance familiar dos neuróticos"). Um ganho certo da reflexão sobre esses temas se tem, quando quer as valorizações quer as suspeitas se voltam mais aos processos psicológicos em jogo do que às metas em que desembocam.

Uma outra importante aquisição do modelo é a capacidade de dar conta da interação e negociação entre vivências idiossincráticas e dinamismos intrapsíqucos e ambiente sócio-cultural ou, para usar termos winnicottianos, de abordar a religião como fenômeno transicional, capaz de "fazer a ponte" (bridging) entre mundo subjetivo e mundo objetivo. Isso comporta, também no caso da religião, uma abordagem caracterizada pela criatividade, entendida como "uma espécie de coloração do inteiro posicionamento frente às realidades externas" (Winnicott, 1975). Oposta à "complacência" que nutre uma adaptação passiva às demandas do exterior, a "apercepção criativa" anima a construção de um self verdadeiro. Também desse ponto de vista, a experiência da religião pode constituir um elemento da ontogênese do sujeito psíquico.

Mais em particular, o modelo que considera a ilusão religiosa como um fenômeno transicional parece particularmente fecundo de perspectivas heurísticas e clínicas. Permite colher a vitalidade psicológica da experiência religiosa e, ao mesmo tempo, sua ambivalência. De fato, a possibilidade de fruir da religião como potencial transformativo da personalidade é acompanhada de uma grande vulnerabilidade a distorções patogênicas, particular- 
mente marcadas por redobramentos defensivos narcísicos e projeções que desembocam em modalidades perversas (por exemplo, autísticas ou fetichistas) de estruturação e evolução da mesma experiência religiosa. Além disso, o modelo sublinha os vínculos da representação de Deus com a represent ação dos objetos primários e do self e com a história relacional do sujeito, a partir das mais precoces experiências parentais; mesmo se fica em aberto o problema do desembaraçamento das relações entre representação inconsciente e posicionamento pessoal. Revaloriza os componentes emotivo-afetivos, éticos, estéticos e lúdicos que sustentam, no indivíduo, uma criativa apropriação do universo simbólico religioso, ao lado, e mais incisivamente, dos componentes cognitivos e sociais. Dá conta do fato de que o posicionamento pessoal do crente está sempre em tensão dialética com as formas institucionalizadas da religião (dogma, culto, organização), recortando-se uma "zona intermediária" entre subjetividade e objetividade. Assinala a interação de símbolos e ritos religiosos codificados com o processo pessoal de "conferimento de sentido", que pode explicar quer a aceitação quer a recusa da crença ou a sua utilização em formas des-viadas e per-versas e/ou criadoras e inovadoras, com relação ao sistema simbólico religioso institucional.

O modelo dá conta, também, dos resultados negativos e desestruturantes do encontro do indivíduo com a religião. Nenhuma garantia, com efeito, é dada, de que a religião, na experiência individual, seja vivida como um objeto transicional. A possibilidade de ilusão, de brincadeira e de criatividade no uso dos objetos religiosos não está garantida da armadilha de fazer delas, por exemplo, um uso "autístico" ou "fetichista".

$\mathrm{E}$ assim, a fé se corrompe em ideologia e a relação religiosa expressa pelo "Creio em Deus" se torna um assentimento ao conteúdo doutrinal "Creio que Deus...". Os objetos religiosos se reduzem a talismãs, a criatividade pessoal, a fantasia e a brincadeira são mortificadas em estereotipia e repetição; o simbolismo religioso decai em realismo e fundamentalismo literalista no confronto com os textos sagrados; os ritos religiosos se degradam em rituais obsessivos, ou esotéricos, para iniciados; a pertença à igreja ou grupo religioso se manifesta em fanatismo, ou gregarismo e dependência; a confiança no líder degenera em enfraquecimento da crítica; a solidari- 
edade e coesão interna se cristalizam em fechamento e afastamento do exterior, sectarismo, medo do mundo e impossibilidade de crescer.

\section{Para um uso psicológico, não apologético, do modelo}

Mérito notável do modelo é o de ter nascido da prática clínica e de apresentar-se como suficiente e coerentemente estruturado, de modo a poder ser verificado (ou falseado) no curso do tratamento psicanalítico. Ficamos, pelo contrário, perplexos diante das tentativas de um uso impróprio, em função teórico-apologética, da parte de crentes e teólogos, como se aí se entrevisse uma prova psicológica da existência de Deus.

Ao contrário, a constatação de que a religião é capaz de fornecer experiências significativas na esfera transicional deixa intocado o juízo de verdade acerca de seus conteúdos, contra toda apologética e toda forma de reducionismo. O psicólogo não está interessado na verdade-falsidade dos conteúdos da ilusão religiosa. Posto que a ilusão é considerada como uma brincadeira do sujeito com a realidade, para o psicólogo a ilusão é verdade $i$ ra enquanto ilusão (isto é, função psíquica).

A propósito, deveria ser iluminador e exemplar o posicionamento do próprio Winnicott. Surpreende, de fato, que o interesse de tantos homens de religião pelo modelo winnicottiano não encontre correspondência em um interesse explícito e tematizado de Winnicott pela religião. Ele se interessa pela crença em Deus só e enquanto ela, proporcionando experiências significativas na esfera transicional, contribui para a tarefa nunca terminada do desenvolvimento do self, como uma das possíveis exteriorizações da capacidade de crer em alguma coisa; isto é, no caso específico da religião, como capacidade de crer e também de não crer, ou de permanecer, criativamente, na dúvida (Winnicott, 1989). Essa capacidade, que se enraíza na confiança básica originada das mais precoces experiências de cuidado é uma das manifestações da capacidade de ficar sozinho (Winnicott, 1982). E é sempre nessa perspectiva que Winnicott recolhia a valência psicológica e a função instrumental da pertença a uma religião, e com seu eficaz e personalíssimo 
estilo paradoxal, sublinhava que uma educação religiosa, verdadeiramente libertadora deve colocar a pessoa em condição de libertar-se, também, dos nós que podem ter sido constituídos pelas próprias formas religiosas instit ucionais. De sua própria experiência pessoal, ele, não crente, dizia: "Sempre me alegrei de que minha educação religiosa tenha sido tal que me permitisse poder distanciar-me da religião" (Winnicott, 1989).

Alguma consideração à parte merece a proposta de Rizzuto. A influência de suas obras revela-se sempre crescente na literatura psicanalítica internacional da religião e tem aberto um amplo debate, desde a publicação de The birth of the living God (1979), seja pela relevância e novidade de conteúdos e métodos, seja pela fecundidade dos desenvolvimentos e das possibilidades de ulterior pesquisa que abre, também, a partir de algumas considerações críticas de sua proposta.

Importante e obrigatório é um reconhecimento preliminar: a obra de Rizzuto oferece um exemplo de correção epistemológica no tratar as vivências psíquicas da religião enquanto tais. Ela está animada por interesses de conhecimento do funcionamento psíquico e por interesses pragmáticos que, surgidos no curso da prática clínica, reconduzem à clínica. Em uma palavra, seu estudo visa a uma melhor compreensão da psique, não a uma melhor compreensão dos conteúdos da religião.

Dito isso, destaco que é extremamente intrigante o eco suscitado, na obra de Rizzuto, pelo tema das relações entre representação inconsciente e figuração consciente de Deus, em particular, quando se pensa numa possível trans formação da representação, que motive uma mudança na adesão pessoal (conversão ou afastamento). Não obstante as aberturas propiciadas por Rizzuto, parece tarefa ainda à frente a construção e a verificação, mediante a observação clínica, de um modelo que dê razão quer da estruturação, na idade infantil, da representação de Deus a partir das representações dos objetos primários e do self, quer das transformações de tal representação infantil de Deus a serviço da vida psíquica.

Quanto à primeira questão, as respostas apresentadas na literatura estão longe de ser unívocas; a mais convincente, mas à espera de verificação 
empírica, fala de "transferência simbólica", . Concedido, a seguir, que as crenças religiosas não são exaustivamente explicadas pelos conceitos de projeção, ilusão e objeto transicional, que remetem, por sua vez, à representação mental, deve ser destacado que entre representação dos objetos primários e representação de Deus existe uma continuidade não necessariamente linear, mas dependente dos resultados da dialética e do confronto com a representação do self, dentro do campo de ação do processo primário.

Quanto à segunda questão (como e em que condições é possível uma remodelação da representação de Deus), Rizzuto faz referência a eventos importantes da experiência relacional, possíveis ao longo de todo o ciclo de vida, que incidem e reestruturam a representação do self, dos objetos primários e de sua relação dialética. Certamente, isso é possível por meio das modificações intrapsíquicas e relacionais profundas que se podem verificar no curso de uma análise. Se é possivel instaurar um relacionamento maduro com os próprios genitores, será possível, também, uma representação de Deus, não infantilmente ligada à nostalgia do pai. E com isso, conseqüentemente, caem as contraposições entre permanência da representação de Deus e resultado de uma análise ou entre representação de Deus e a possibilidade mesma de análise, como aconteceu sustentarem (também por causa de uma apressada sobreposição entre representação de Deus e fé em Deus), respectivamente, Melanie Klein e Jacques Lacan. Também o ateísmo tem uma matriz relacional e, do ponto de vista psicodinâmico, se apresenta como uma das possíveis modalidades da capacidade de "crer em" (Winnicott). Não é que a religião seja uma forma relacional (patológica) de que o ateísmo simplesmente marcaria a ausência. Se de Deus não podemos deixar de ter uma representação, a partida da saúde mental se joga antes na modalidade (egossintônica ou egodistônica) da escolha, consciente e subordinada, de aderir com a fé ou de abster-se, com o ateísmo, daquela representação que, de qualquer modo, está em cada um.

8 Veja-se Milanesi, G. \& Aletti, M. (1973), Elle Di Ci, 101-120, em particular 115s. 
De outra parte, se a transformação da representação de Deus supõe uma reestruturação de memórias compostas a partir de múltiplos níveis, numa gama que vai do visceral ao conceitual, coloca-se a questão da possibilidade, da eficácia, dos percursos e dos resultados dos estímulos conscientes (suplemento de informações religiosas, freqüência a ritos coletivos, inserção em uma cultura ricamente religiosa etc.) sobre essa radical mudança. E também se poderia perguntar se as transformações eventualmente verificadas devem ser reconduzidas à força motivacional e transformativa inserida no sistema simbólico religioso (conteúdo da mensagem) ou à experiência relacional, que implica movimentos transferenciais e contratransferenciais, conexa ao encontro interpessoal, mediador da mensagem. É claro que isso levanta muitas interrogações (e alguma perspectiva) sobre os níveis a que se endereça a educação religiosa, assim como a ação pastoral, e repropõe ao psicólogo a complexidade dos fenômenos de transformação profunda, como o da conversão religiosa. Também sob o perfil metodológico, a obra de Rizzuto, enquanto põe à disposição importantes inovações, estimula seu aprofundamento, precisão e sistematizałẫã consciente e de que também a figuração e a conceituação de Deus estão ancoradas em representações objetais inconscientes, comportam a elaboração de novas metodologias e instrumentos de estudo para a religiosidade, solidamente ancoradas na clínica, entendida, não necessariamente, como prática terapêutica, mas como horizonte heurístico da observação interpretadora. A reflexão teórica poderia, antes de tudo, interrogar-se sobre a possibilidade de uma "representação inconsciente de Deus".

Aqui, minha opinião se diferencia da de minha caríssima amiga Rizzuto. Eu creio que, não obstante o profundo enraizamento nas dinâmicas inconscientes e pré-conscientes, falar de "representação inconsciente de Deus" pode revelar-se impróprio. Na medida em que é inconsciente, a representação não está orientada por um nome, não é definível com uma especificação. É a cultura, a religião que dá um nome ao objeto do desejo. A representação objetal parece mais adequadamente pensável como matriz sempre insaturada, moda- 
lidade relacional sempre aberta, magma informe e, por isso, capaz de informar com ela mesma os objetos reais: afetos, relações, crenças.

Prefiro falar de disposições representacionais e relacionais, de todo modo, estruturantes da personalidade e de suas experiências mais profundas, que abrem para percursos sucessivos e, no caso específico da religião, na direção quer da fé quer da não crença. Essas relações supõem pré-condições psicológicas (inespecíficas e, certamente, a-religiosas) como a capacidade de "crer" e de confiar, a capacidade de relações objetais suficientemente estruturadas, a capacidade de simbolização, a capacidade de atribuir significado aos acontecimentos, a capacidade de distinguir entre objeto e uso do objeto. Mas a experiência religiosa requer, especificamente, a capacidade de dar um nome à experiência de crer, que deriva da interação do sujeito com o sistema simbólico religioso e, para o homem de fé cristã, supõe a palavra reveladora de Deus e a capacidade de responder, com toda a sua pessoa, à interlocução iniciada por Deus.

Do ponto de vista da prática analítica, a convicção de que todos têm alguma representação de Deus, prevalentemente inconsciente, induz a sublinhar o óbvio, quem sabe, às vezes, escotomizado: não só o paciente, mas também o terapeuta, não pode deixar de ter uma. E se a representação de Deus é a resultante da interação entre as representações dos objetos primários e do self, resulta muito provável que a representação que o paciente estruturou se apresente como importante elemento da psicodinâmica por ele colocada em campo e operante, também, na transferência. Quanto ao psicanalista, sua representação inconsciente de Deus poderia influir na avaliação e no tratamento da religiosidade do paciente, e poderia jogar na contratransferência. A vexata quaestio das relações entre religiosidade do paciente e religiosidade do terapeuta é novamente colocada aqui num outro, e mais elevado, nível de complexidade, que enseja novas tarefas de aprofundamento, quer da prática clínica, quer da formação dos próprios psicoterapeutas. 
Aletti, M. (2004). The Figure of Illusion in Psychoanalytical Literature of Religion. Psicologia USP, 15 (1), 163-190.

\begin{abstract}
This paper outlines the history and evolution of the model of illusion applied to the religious experience, based on conceptions from Freud, Pfister, object relations theorists, Winnicott, Vergote and Rizzuto. It also delineates the possibilities originated by these theoretical contributions, along with their limitations.
\end{abstract}

Index terms: Psychoanalysis. Religion.

\title{
Referências
}

Akhtar, S., \& Parens, H. (Eds.). (2001). Does God help? Developmental and clinical aspects of religious belief. Northvale, NJ: London: Jason Aronson.

Aletti, M. (1998). La religione come vissuto psichico. In A. Fabris \& Gronchi (Eds.), Il pluralismo religioso. Una prospettiva interdisciplinare (pp. 74-99). Cinisello Balsamo: San Paolo.

Aletti, M. (2000a). Il contributo di Ana-María Rizzuto alla lettura psicoanalitica del vissuto religioso. Introduzione all"edizione italiana di A.-M. Rizzuto, Perché Freud ha rifiutato Dio? (pp.vii-xxiii). Torino: Centro Scientifico Editore.

Aletti, M. (2000b). Psicologia del profondo e religione. Verità religiosa e verità psicologica. Introduzione all'edizione italiana di M. Palmer, Freud, Jung e la religione (pp.ix-xxii). Torino: Centro Scientifico Editore.

Aletti, M. (2000c). La rappresentazione di Dio come oggetto transizionale illusorio. Rivista di Psicologia Analitica, (nuova serie, 9), 109-134.

Aletti, M. (2001). Il contributo di Ana-María Rizzuto alla psicologia della religione. In M. Aletti \& G. Rossi (Eds.), L'illusione religiosa: rive e derive (pp. 15-24) .Torino: Centro Scientifico Editore.

Aletti, M., \& Ciotti, P. (2001). The birth of the believing man. Prospects for and problems with the object relations theory applied to religion. In M. Aletti \& G. Rossi (Eds.), L'illusione religiosa: rive e derive. (pp.297-302).Torino: Centro Scientifico Editore. 
Argentieri, S. (2000). Il presente di un'illusione. Micromega. Almanacco di Filosofia, (2), 219-227.

Beit-Hallahmi, B. (1995). Object relations theory and religious experience. In R. W. Hood (Ed.), Handbook of religious experience (pp. 254-268). Birmingham, AL: Religious Education Press.

Beit-Hallahmi, B. (1996). Psychoanalytic studies of religion. A critical assessment and annotated bibliography. Westport, CT: Greenwood.

Black, D. M. (1993). What sort of a thing is a religion? A view from object-relations theory. The International Journal of Psycho-Analysis, 74, 613-625.

Fairbairn, W. R. D. (1955). Observations in defence of the object-relations theory of the personality. British Journal of Medical Psichology, 28, 144-156.

Finn, M., \& Gartner, J. (Eds.). (1992). Object relations theory and religion. Clinical applications. Westport, CT; London: Praeger.

Freud, S. (1887-1904). Lettere a Wilhelm Fliess. 1887-1904. Torino: Bollati Boringhieri (Collana Gli Archi) 1990. 1a ediz. Boringhieri, 1986.

Freud, S. (1969). Leonardo da Vinci e uma lembrança de sua infância. In S. Freud, Edição standard brasileira das obras psicológicas completas de Sigmund Freud (Vol. XI, pp. 53-124). Rio de Janeiro: Imago. (Trabalho original publicado em 1910)

Freud, S. (1975). Moisés e o monoteísmo. Três ensaios. In S. Freud, Edição standard brasileira das obras psicológicas completas de Sigmund Freud (Vol. XXIII, pp. 13161). Rio de Janeiro: Imago. (Trabalho original publicado em 1934-1938)

Freud, S. (1976). O estranho. In S. Freud, Edição standard brasileira das obras psicológicas completas de Sigmund Freud (Vol.VI, pp. 273-318). Rio de Janeiro: Imago. (Trabalho original publicado em 1919)

Freud, S. (1976). Psicopatologia da vida cotidiana. In S. Freud, Edição standard brasileira das obras psicológicas completas de Sigmund Freud (Vol. VI, pp. 11332). Rio de Janeiro: Imago. (Trabalho original publicado em 1901)

Freud, S. (1987). O futuro de uma ilusão. In S. Freud, Edição standard brasileira das obras psicológicas completas de Sigmund Freud (Vol. 21I, pp. 15-71). Rio de Janeiro: Imago. (Trabalho original publicado em 1927)

Freud, S. (1987). O mal-estar na civilização. In S. Freud, Edição standard brasileira das obras psicológicas completas de Sigmund Freud (Vol.XXI, pp. 73-148). Rio de Janeiro: Imago. (Trabalho original publicado em 1929)

Freud, E., \& Meng, H. (Orgs.). (2001). Cartas entre Freud e Pfister: 1909-1939. Um diálogo entre a psicanálise e a fé cristã (Ditimar Junge \& Karin H. K. Wondracek, trad.). Viçosa, MG: Ultimato. 
Guntrip, H. (1956). Mental pain and the cure of souls. London: Independent Press.

Guntrip, H. (1969). Religion in relation to personal integration. British Journal of Medical Psichology, 42, 323-333.

Jacobs, J. L., \& Capps, D. (Eds.). (1997). Religion, society, and psychoanalysis. Readings in contemporary theory. Boulder, CO: Cumnor Hill; Oxford: Westview Press. Trad. Ital. Religione, società e psicoanalisi. Torino: Centro Scientifico Editore (in press).

Leavy, S. A. (1988). In the image of God. A psychoanalist's view. New Haven, CT: Yale University Press.

Malony, H. N., \& Spilka, B. (Eds.). (1991). Religion in psychodynamic perspective. The contributions of Paul W. Pruyser. New York, NY: Oxford University Press.

Meissner, W. W. (1984). Psychoanalysis and religious experience. New Haven, CT; London: Yale University Press.

Meissner, W. W. (1987). Life and faith: Psychological perspectives on religion experience. Washington, DC: Georgetown University Press.

Meissner, W. W. (2001). So help me God! Do I help God or does God help me? In S. Akhtar \& H. Parens (Eds.), Does God help? Developmental and clinical aspects of religious belief (pp. 77-126). Northvale, NJ; London: Jason Aronson.

Milanesi, G., \& Aletti, M. (1973). Psicologia della religione. Leuman (Turim): Elle Di Ci.

Pfister, O. (2003). A ilusão de um futuro. Um embate amigável com o prof. Dr. Sigmund Freud. In Karin H. K. Wondracek (Org.), O futuro e a ilusão. Um embate com Freud sobre Psicanálise e Religião (pp. 17-56). Petrópolis, RJ: Vozes. (Trabalho original publicado em 1928)

Pruyser, P. W. (1977). The seamy side of current religious beliefs. In H. N. Malony \& B. Spilka (Eds.), Religion in psychodynamic perspective. The contributions of Paul W. Pruyser (pp. 47-65). New York: Oxford University Press.

Pruyser, P.W. (1979). Psychological roots and branches of belief. In H. N. Malony \& B. Spilka (Eds.), Religion in psychodynamic perspective. The contributions of Paul W. Pruyser (pp. 155-169). New York: Oxford University Press.

Pruyser, P. W. (1983). The play of the imagination. Toward a psychoanalysis of culture, New York: International Universities Press.

Rizzuto, A.-M. (1979). The birth of the living God. A psychoanalytic study. Chicago; London: The University of Chicago Press. Trad. it. La nascita del Dio vivente. Studio psicoanalitico. Roma: Borla, 1994.

Rizzuto, A.-M. (1992). Afterword. In M. Finn \& J. Gartner (Eds.), Object relations theory and religion. Clinical applications (pp. 155-175). Westport, CT; London: Praeger. 
Rizzuto, A.-M. (Winter 1996/Spring 1997). Belief as a psychic function. Newsletter. Psychology of Religion. American Psychological Association Division 36, 1-7.

Rizzuto, A.-M. (1998a). Por que Freud rejeitou Deus. São Paulo: Loyola (2001).

Rizzuto, A.-M. (1998b) Psychoanalytic psychotherapy and pastoral guidance. Journal of Pastoral Care, 52 (1), 69-78.

Rizzuto, A.-M. (2001). Vicissitudes of self, object, and God representations during psychoanalysis/Trasformazioni delle rappresentazioni del Sé, dell'oggetto e di Dio in psicoanalisi. In M. Aletti \& G. Rossi (Eds.), L'illusione religiosa: rive e derive (pp. 25-55). Torino: Centro Scientifico Editore.

Salomé, L. A. (1931). Carta Aberta a Freud.São Paulo: Princípio.

Vergote, A. (1966). Psychologie religieuse. Bruxelles: Charles Dessart. Trad. it. Psicologia religiosa, Torino: Borla, 1967. Trad. inglese The religious man. A psychological study of religious attitudes. Dublin: Gill \& Macmillan, 1969.

Vergote, A. (1978). Dette et désir. Deux axes chrétiens et la dérive pathologique. Paris: Seuil. Trad. norte-americana Guilt and desire: Religious attitudes and their pathological derivatives. New Haven, CT: Yale University Press, 1988.

Vergote, A. (1995). Debate concerning the psychology of religion. The International Journal for the Psychology of Religion, 5(2), 119-123.

Vergote, A. (1997). Neither masterly nor ancillary. In J. A. Belzen \& O. Wikström (Eds.), Taking a step back. Assessments of the psychology of religion (pp. 159-169). Uppsala: Acta Universitatis.

Wallace, E. R. (1991). Psychoanalytic perspectives on religion. International Review of Psycho-Analysis, 18, 265-278.

Winnicott, D. W. (1975a). O brincar e a realidade. Rio de Janeiro: Imago.

Winnicott, D. W. (1975b). A localização da experiência cultural. In D. W. Winnicott, $O$ brincar e a realidade (pp.133-143). Rio de Janeiro: Imago.

Winnicott, D. W. (1975c). O uso de um objeto e relacionamento atraves de identificações. In D. W. Winnicott, O brincar e a realidade (pp. 121-132). Rio de Janeiro: Imago.

Winnicott, D. W. (1982a). O ambiente e os processos de maturação: estudos sobre a teoria do desenvolvimento emocional. Porto Alegre: Artes Médicas.

Winnicott, D. W. (1982b). A capacidade estar só. In D. W. Winnicott, O ambiente e os processos de maturação: estudos sobre a teoria do desenvolvimento emocional (pp. 31-37). Porto Alegre: Artes Médicas.

Winnicott, D. W. (1989a). O aprendizado infantil. In D. W. Winnicott, Tudo começa em casa (pp. 111-116). São Paulo: Martins Fontes. 
Winnicott, D. W. (1989b). Objetos transicionais e fenômenos transicionais. In D. W. Winnicott, $O$ brincar e a realidade (pp. 13-44). São Paulo: Martins Fontes.

Recebido em 03.08.2004 Aceito em 24.11.2004 